\title{
THE USE OF THE CONCEPT OF RECIPROCITY FOR THE INTERPRETATION \\ OF CONTEMPORARY ADVANCED INDUSTRIAL SOCIETIES: AMBIGUITIES AND ASSETS ${ }^{1}$
}

\author{
Enzo MINGIONE \\ University of Milano-Bicocca
}

ABSTRACT: This paper analyses reciprocity as a tool for the interpretation of modern industrial societies and some of the problems we find when we transfer the anthropological concept into sociology.

This paper deals, in a preliminary and schematic way, with the use of reciprocity as a tool for interpreting modern industrial societies. Within my approach it is necessary to clarify immediately that reciprocity is not only a resource but, as a diffused and variable form of social relation, also an inextricable mix of resources and obligations. This fact must not be forgotten in order to avoid the ambiguities and myths that are usually attached to the use of this and related concept, in particular the fashionable one of social capital.

An anthropological approach allows us to identify a typology of social relations that is significant in terms of both content and organizational logic. It is a question of adapting the concepts formulated to serve micro analysis so that they are compatible with an approach oriented to the macro analysis of social organization.

Reciprocity is a type of social relation that only has meaning within an organizational system, because exchange is not concluded in a single act, transactions are potentially inequitable and the commitment to reciprocity is

1 Este artículo reproduce la comunicación presentada en el debate inaugural de ESF-SCSS Exploratory Workshop "Reciprocity as a Human Resource», Barcelona, septiembre 2001.

ENDOXA: Series Filosóficas, n. ${ }^{\circ} 15,2002$, pp. 51-58. UNED, Madrid 
vague or implicit. For this reason reciprocity refers to forms of social organization involving a varying but limited number of individuals who know specifically of each other's existence and engage in personal contact. Both in the case of reciprocity and in that of association the sense of the social relationship is given by different types of common interests, and this is reflected in the underlying form of social organization. To take this distinction to its extreme limit, one could say that whereas in reciprocity the defence of a group interest requires some members to make sacrifices in favour of the group, associative relations advance the interests of all the members of an association and defend them against those who are not members. The difference becomes evident if two examples from opposite ends of the spectrum, that is to say less prone to assuming a mixed meaning, are considered; for example family and trade union. The common interest of the family assumes a meaning independently of its members' individual interests and involves unequal sacrifices and exchanges. The common interest of the trade union is not separate from that of its members and whenever some of them systematically benefit more than others from trade union action, this weakens the organization and can in the long run lead to its break-up.

The question of the group interest having priority over the immediate interests of individuals constitutes the core of the concept of reciprocity as a factor of social organization. But this constitutes only the general universal frame of the concept even if it evokes already two important questions: the fact that in order to prevail over potentially conflicting individual interests the goals, order and ethical system of the reciprocal groups must be embedded deeply, even if for various different reasons, in individual consciousness; and the strict interconnection between advantages and obligations. The transfer of the concept into sociological analysis imposes facing serious problems connected with the historical and cultural variability of the contexts of reciprocity.

\section{Historical variability}

This is a major problem particularly because it has been ignored by scholars: within micro approaches reciprocity is not considered as an historical and changing construction, while sociology has often thought of community organizations as disappearing or becoming less and less important within the mo- 
dernization process. On the contrary we now know that reciprocity is persistently important but also highly changing within the processes of modernization. Let us mention some traces of change.

1) Historians have noted that, particularly in continental Europe, the industrialization and urbanization process has weakened the influx of local communities in favour of kinship and, later on, companionship and friendship.

2) The ethnic basis for reciprocity has reappeared in new, various and transformed ways in migration chains and ethnic businesses.

3) The family/kinship basis for primary reciprocity has been greatly modified from its patriarchal/clannish origins into various selective and individualistic mixes between nuclear households and close-by or preferred kin relations.

4) High geographical and social mobility, and more recently new communication technologies, have promoted opportunities for reciprocity nets that were previously difficult, at least on a mass scale.

5) Urbanization itself has promoted new opportunities for reciprocity relations: for example, neighbourhood but also commuters travelling at the same time on the same bus or train.

In general, even if it is a risky operation, it is possible to point to two trends in the transformation of the social basis of reciprocal organizations: a tendency towards less unbalanced distribution of power (from patriarchy to democracy?); an increasing importance of voluntary, chosen selective relations compared to strictly attributed ones. These trends are more powerful within more affluent communities freed from the constraints of everyday needs which, on the contrary, impose a strict line of command and moral obligations and lack of individual choice.

\section{Cultural variability}

This is even more problematic. If we start from anthropological experience the variety of reciprocal organizations is nearly infinite in terms of cultural forms and rules of exchange, rituals and norms. For groups with clear and fixed goals (like the genetic reproduction of the group for families) we can 
limit and master the complexity but for other cases it is more difficult. Let us look again for some traces for discusssion.

1) The first area of variability concerns the strength of the network and the amount and quality of resources circulating within it. Each individual is involved in many different and changing systems of reciprocity, from the cohabiting family to the kinship network, from one or more circles of friends to the neighbourhood or village system, from the firm where one works or the school where one studies to companions at work or school. These systems may be more or less strong and more or less rich in resources, in the sense of being able to subordinate immediate individual interests to those of the system itself. Systems rich in resources are also stronger for reasons based on an indirect application of Weberian rationality in that the possibility of more substantial compensation is evident. But the reverse is not true: a poor and socially isolated family is still a strong system with few resources. Granovetter's idea of strong and weak ties falls in this area of variability. We know better now that the difference is mainly given by the quality of resources (and obligations) circulating in strong, closed and homogeneous networks (more supportive but within a more limited range of resources) with respect to looser and more heterogeneous networks. And the difference can go well beyond the application in the case of finding a job.

2) The second area of variation is the voluntary versus attributive nature of reciprocal groups. Here it is interesting to point to the mixes like the $\mathrm{cu}-$ rrent ones of kinship or ethnicity: how much and under what conditions a member of a network can select the relations (and consequently resources and obligations) to which (s)he is bound and with what consequences in terms of life strategies and opportunities.

3) A third area of diversity is the structure of power within the network. Here I repeat some considerations already made in Fragmented Societies. In as much as they are socio-organizational contexts, reciprocal systems are by definition systems of power. The family and the patriarchal power structure are the themes that have been studied most. Also in terms of power, reciprocal contexts are different from bureaucratic or associative ones. Not only is a father-boss different from a foreman, but his power tends to change in different directions, with the growth of technologically advanced modern family businesses or with the urbanization of the poor rural strata in underdeveloped countries and the de- 
velopment of the informal sector. The diversity and the changes in the power structure of reciprocal systems are both connected to the meaning and importance of their common goals and to some general social conditions. In theory, it is true that reciprocal patterns of social organization are originally far from individual autonomy and, consequently, the power structure of organizations based on reciprocity can be extremely authoritarian. Take the example of the original legal structure of the Roman family where the pater familias had the right of life and death over all the members, including adult children. Conversely, in other cases the power structure can be extremely loose and democratically distributed among members; this often occurs in voluntary networks. The best example is that of a network of friends. But, in this case too, where the objective of the group is more significant, it is also likely that the power structure will change and become more authoritarian. An instance is that of a group of friends who decide to go on an adventurous holiday together involving difficult environmental conditions. A much more unequal power structure will probably emerge. One of the friends will act naturally as a leader and those least able to cope with the difficult conditions will be denigrated and relegated to a subordinate condition. This may eventually lead to a partial or total discontinuation of the friendship. Take a second example. The power structure of a group of teenage friends changes completely when the group becomes transformed into a street gang. Not only does the structure become authoritarian and hierarchical with a leader, deputy leader, etc., but participation in the group may possibly lose its voluntary character. When this happens, members who try to leave the gang are threatened. However, reciprocal patterns of social organization may roday be more open to changing their internal power structure in order to accommodate an increasing need for individual autonomy and self-fulfilment than large bureaucratic structures, at least under certain social conditions. This is a point that the classical tradition in sociology has entirely overlooked. The best example are the transformations of the family power structure in the industrialized countries, particularly the changes in social groups with average or above-average incomes. Age and gender asymmetry have decreased and the scope of the organization is more often negotiated than dictated by a single member: individual aspirations and vocations are taken into consideration even when they appear to be in conflict with previous assumptions about the perspective and scope of the 
family. The greater flexibility of reciprocal networks in accommodating individual autonomy compared to large organizations is not a paradox, considering their more manageable size or, in other words, the fact that individuals are closer to the decision-making apparatus and so can better negotiate with and influence the group action strategies. Correspondingly, the decision-making apparatus may be more receptive to individual needs and aspirations. This flexibility and receptivity are found only in societies in the industrial age when the diffusion of competitive behaviour opportunities and the parallel emergence of individual selfconsciousness leads to the dismantling of the social order based on a strict subordination of individual interests to those of groups based on reciprocity. Furthermore, this process is conditioned by the fact that the opportunities available to such groups for attaining their goals are not too restricted. This is particularly visible in the case of the family. The most egalitarian processes of renegotiation of the power structure are more likely in the case of families with a full range of opportunities than in that of families condemned to struggle for bare survival.

4) Perhaps the area of variability which is more important and at the same time more difficult to analyse relates to the goals of the group, its ties and moral structure that justify the superiority of group interests and the specific modes or rituals of their implementation. For interpretative sociological purposes, this exercise cannot stop at a purely descriptive level but has to be grounded in the general social order. In this sense, the analysis of reciprocal systems is a constitutional part of any theory of embeddedness. In conclusion, let us look briefly at some problems concerning this area of variability.

The limits of reciprocity:

tensions and contradictions in respect of the general social order

A first problem arises from the fact that within the wide range of reciprocal networks there are some based on goals or power structures that are highly contradictory with respect to the moral basis of society in general. They have a strong internal legitimation with precise rules of honour for circulating resources and obligations, channel loyalty and trust but are disruptive of the general social order. And this is not only so in the clear case of criminal organizations 
like mafia groups but also in more ambiguous instances. Let us take the case, recently reported in the press (Il Corriere della Sera, 2-9-2001), of what happened in the village of Alinagar in northern India. A 17 -year-old man and a 16-year-old woman of different casts were seen together having a conversation by a neighbour who reported the fact, strictly forbidden in the village, to the family of the girl, member of the powerful agricultural cast dominating the region. The two teenagers were privately tried before an assembly of adult village members, including the families of both, condemned to death and strangled. This is a limit case where we have no doubts that the end of story is totally unacceptable but, on the other hand, the internal traditional order of reciprocal groups may contribute to a sufficient level of trust to be used in new opportunities being combined with the preservation of social integration. This occurs within rules that by definition (the priority of the interests of the specific group) are inconsistent with equal opportunities or other founding principles of the modern social order. Thus, the boundaries berween legitimate particularistic reciprocal behaviour and disruptive behaviour are not so clear as they appear from the above radical examples.

There is a second mode of taking into consideration the inconsistency between reciprocal networks and principles of modern societies, in particular equal opportunities and selection according to universalistic professional competence rules. I take into consideration here only the particular case of the family business even if the problem is much wider from the point of view of sociological analysis and again with ambiguous boundaries between forms of patronage (in some cases even illegal, but promoting the social insertion of specific groups) versus forms of universalism. From the angle of the family business the possibility to recruit members of the kin network is a legitimate form of buying loyalty cheaply, but it is also an obligation which may have a negative impact on the business. There is what I call "the dilemma of the stupid or lazy cousin». A small business may be successful if the relatives employed in the venture are competent enough and hard workers or unsuccessful if they are not. And the rules of the kinship group leaves limited options for selection: often you have to take all or nothing.

There is also a more general aspect of the problem which is clearly reflected in the Italian data on employment of highly skilled and educated workers in Italy. The persistent dominance of small family ventures, which are naturally less inclined to recruit highly skilled workers and managers as they conflict with the family's aims, distorts the relation between economic develop- 
ment and growth of education opportunities. The demand for highly educated workers in industry is chronically depressed and the competition for jobs is relegated to the public sector or large concerns. At the same time, a considerable group of young males do not continue their studies as they are drawn away early to work in small businesses (in the late nineties, only $75 \%$ of young males in the wealthy northern regions were in high school against an average of $85 \%$ ). The changing direction of the gender bias in family education strategies (from investing mainly in male education to investing more in female education) is also accentuated.

The positive cooperative resources of reciprocity: social capital and the third sector

If we consider only what has been said up to now, the impression gained is a negative view of reciprocity as a human resource. This is certainly not my intention. Reciprocity, with its limits and obligations, remains the most powerful factor for the creation of collaborative attitudes, particularly now that the highly bureaucratised and standardised forms of organization are declining and less effective. The problem is what forms of reciprocity can develop that instead of being disruptive of some ethical principles of the modern age (like equal opportunities, welfare rights and social justice) effectively enforce them. Here I just mention the two areas of sociological attention in this field that I will develop more in my spoken intervention and in the final draft of this paper.

The first area of debate concerns social capital and explores the possibility that the resource is less unequally distributed than physical and cultural capital and that, particularly in some contexts, it can offset the closures created by social inequalities and discrimination.

The second area to be developed concerns the third sector, non-profit and solidarity economies and how the development of this area of activities, strongly grounded in the development of new forms of reciprocity, may offset the decline of the welfare state within a persisting welfare culture. 